\title{
Individual and Environmental Factors Associated with Tobacco Smoking, Alcohol Abuse and Illegal Drug Consumption in University Students: A Mediating Analysis
}

\author{
Laura Delgado-Lobete ${ }^{1, *,+} \mathbb{C}$, Rebeca Montes-Montes ${ }^{2, *,+}+\mathbb{D}$, Alba Vila-Paz ${ }^{1}$, \\ José-Manuel Cruz-Valiño ${ }^{1,3}$, Berta Gándara-Gafo ${ }^{1}$, Miguel-Ángel Talavera-Valverde ${ }^{1}$ (D) \\ and Sergio Santos-del-Riego ${ }^{1,4}$ \\ 1 Health Integration and Promotion Research Unit (INTEGRA SAÚDE), Faculty of Health Sciences, \\ University of A Coruña, 15006 A Coruña, Spain \\ 2 TALIONIS Research Group, Faculty of Health Sciences, University of A Coruña, 15008 A Coruña, Spain \\ 3 Institute for Oral Implantology and Rehabilitation of A Coruña (Instituto Coruñés de Implantología y \\ Rehabilitación Oral-ICIRO), 15007 A Coruña, Spain \\ 4 UDC Saudable, Health Promotion Department of University of A Coruña, 15011 A Coruña, Spain \\ * Correspondence: 1.delgado@udc.es (L.D.-L.); rebeca.montes@udc.es (R.M.-M.); \\ Tel.: +34-881-014-339 (R.M.-M.) \\ + Both authors contributed equally to the study.
}

Received: 27 February 2020; Accepted: 24 April 2020; Published: 27 April 2020

\begin{abstract}
Substance abuse is a major and prevalent public health concern among university students. Tobacco smoking, risky alcohol behavior, and illegal drug consumption may lead to health problems and behavioral and academic issues. Several individual and environmental factors associate with substance abuse in this population, and the mediating effect of alcohol abuse in the relationship between tobacco smoking and drug consumption is yet to be explored. The purposes of this study were to evaluate the association of individual and environmental factors and substance use, and to analyze the relationship between tobacco smoking, alcohol abuse, and drug consumption, considering alcohol abuse as a possible mediator. A total of 550 Spanish undergraduate and postgraduate students completed several questionnaires regarding their smoking status, alcohol use, and drug consumption during the last six months. Bivariate and multivariate analyses were conducted to explore associations between factors. Direct, indirect and mediating effects were tested using a partial least squares approach (PLS-SEM). The results indicated that substance abuse is associated with being male, living with other students, and combined substance consumption. PLS-SEM showed a significant effect of tobacco smoking and alcohol abuse on drug consumption. Alcohol abuse plays a mediating role in the relationship between tobacco smoking and drug use.
\end{abstract}

Keywords: university students; substance abuse; alcohol abuse; smoking; tobacco; drug use; environmental factors; mediating analysis

\section{Introduction}

Substance abuse in young adults and university students is a frequent issue and a major public health concern. Recent research indicates that tobacco, alcohol and illegal drug consumption is highly prevalent among Spanish university students, especially regarding cannabis use [1-6]. Prevalence of tobacco smoking in this population ranges from $19 \%$ to $34 \%$ [4-6], and up to $27 \%-59 \%$ of university students in Spain demonstrate alcohol abuse and risky consumption [1,2,4-7]. During the last ten 
years, several studies have estimated that the prevalence of illegal drug consumption in Spanish university students is as high as $16 \%-42 \%[1-6,8]$, and approximately $40 \%$ of students with alcohol issues frequently consume cannabis as well [1].

Tobacco smoking, alcohol abuse, and illegal drug consumption have serious consequences on both individual and public health. Binge drinking is associated with deficits in different executive functions depending on the integrity of the dorsolateral prefrontal cortex, such as verbal and spatial working memory $[9,10]$, difficulties in adaptation to academic life, and poorer performance at university [11-14], especially if students combine alcohol, tobacco, and cannabis consumption [1,15-17]. This is to be expected as cannabis use alone has major effects on several executive functions independently of alcohol abuse, like poorer inhibitory control, working memory, delayed memory and perceptual reasoning [18]. Alcohol and drug abuse in university students are risk factors for later mental health problems as well, including suicidal ideation, later substance use disorder and poorer perceived health and quality of life $[13,17,19,20]$. Risky sexual behavior is one of the consequences of most interest for public health, as young-adult users of alcohol and cannabis are at higher risk for engaging in unsafe sex, including sex under the influence of alcohol and sex without a condom [21,22]. Additionally, drug and alcohol use are associated with higher involvement in risky driving behavior [3].

There are several factors that contribute to explaining substance abuse in university students. Risky behaviors in higher education are heavily influenced by students' expectations and abilities to cope with and to adjust to the highly competitive and challenging new environment [1,23-26]. Students who struggle with transitioning to university are at higher risk for substance abuse, but individual, family and environmental related factors associate with risky behaviors as well. The effects of sex roles on substance abuse is not clear, as some studies report that young men are more likely to engage in risky alcohol and drug behaviors, but others authors have reported the opposite $[2,4,5,27]$. Students living away from the family home (i.e., students who live with other students) are at greater risk of engaging in unhealthy lifestyles, including tobacco smoking, risky alcohol behavior and drug abuse [1,6,8,28,29]. This is of particular importance given that a high percentage of Spanish university students live away from home during the academic year $[8,29,30]$. While there seems to be an interaction between tobacco smoking, risky alcohol behavior and drug consumption, few studies have estimated how tobacco smoking and alcohol abuse in Spanish higher education students interrelate with environmental factors to predict drug consumption.

Apart from individual and environmental effects on substance abuse, use of tobacco and alcohol have been reported as risk factors for illegal drug consumption in higher education students in both cross-sectional and longitudinal studies [1,2,6,31-40]. Tobacco smoking increases the risk of both illicit drug use (i.e., cannabis use, illegal drug use and other non-medical use of prescription drugs) [31-33] and alcohol abuse $[31,34,35]$. Students with risky alcohol behavior are more likely to show illegal drug abuse as well [36,37]. Moreover, both tobacco smoking and alcohol abuse increase the risk of illicit drug abuse in this population [1,6,38-40]. Additionally, health problems occur more frequently and with more adverse consequences in polydrug using students [41]. Given that a high percentage of Spanish university students consume tobacco and show risky alcohol behavior [1,2,4-7], this situation represents a major public health issue.

Overall, previous research shows that tobacco smoking alone predicts both alcohol abuse and drug consumption. As alcohol misuse is influenced by tobacco smoking, while simultaneously increasing the risk of illicit drug use, it may be possible for alcohol abuse to play a mediating effect in the relationship between tobacco smoking and drug use in university students. Exploring this association could contribute to the design of tailored and more effective interventions aimed to prevent both legal and illegal substance consumption. However, to the best of our knowledge, this mediating effect has not been explored yet.

This study aimed to expand on previous research by exploring: (1) the prevalence of tobacco smoking, alcohol abuse, and drug consumption in Spanish university students, (2) the interrelated influence of individual and environmental factors on tobacco smoking, alcohol abuse, and drug 
consumption, and (3) the mediating role of tobacco smoking and alcohol abuse on drug consumption in university students.

The hypotheses of this study for the third aim are as follows:

Hypothesis 1 (H1). Tobacco smoking significantly influences drug consumption.

Hypothesis 2 (H2). Tobacco smoking significantly influences alcohol abuse.

Hypothesis 3 (H3). Alcohol abuse significantly influences drug consumption.

Hypothesis 4 (H4). Alcohol abuse significantly mediates the relationship between tobacco smoking and drug consumption.

\section{Materials and Methods}

\subsection{Study Design, Sample and Procedures}

We conducted a cross-sectional study of a random sample of students at the University of A Coruña (Spain) which holds approximately 13,600 undergraduate and 3150 graduate students. A total valid sample size of 379 was required to assess an expected prevalence of tobacco smoking of $30.1 \%$, alcohol abuse of $26.5 \%$, and drug consumption of $43 \%$, assuming a significance level of $\alpha=0.05(95 \%$ confidence interval) and a maximum margin of sampling error of $5 \%[2,7,8]$.

An online survey was sent to all undergraduate and graduate students' institutional e-mail addresses from February to June 2018 as part of a larger study on healthy lifestyles among University students [42]. The e-mail included information regarding the study objectives and methodology and the link to the online questionnaires. It was stated that the participation was voluntary and data was collected anonymously. This study was approved by the University Research Ethics Committee on February 2018 prior to data gathering (code 20180201).

\subsection{Measures}

Demographic and environmental data included age (in years), sex (man vs. woman), living arrangement (lives with family/partner/alone vs. lives with other students) and living area (urban, suburban or rural). Academic data included student status (bachelor student, master's student or PhD student) and field of study (Arts and Humanities, Engineering and Architecture, Health Sciences, Sciences or Social and Legal Sciences).

Substance abuse assessment included tobacco smoking behavior, alcohol abuse and drug consumption.

\subsubsection{Tobacco Smoking}

Students were asked to answer a question regarding their current tobacco smoking status: (1) never smoked; (2) ex-smoker (have not smoked cigarettes during at least the past twelve months); (3) current smoker ( $<15$ cigarettes per day); and (4) current smoker ( $\geq 15$ cigarettes per day). Students were then classified as non-smoker (status 1 and 2) and current smoker (status 3 and 4) for bivariate and multivariate analyses.

\subsubsection{Alcohol Abuse}

Alcohol abuse was measured with the Spanish version of the Alcohol Use Disorders Identification Test Consumption (AUDIT-C) [7,43]. The AUDIT-C is a widely-used, three-item self-administered screening instrument for alcohol abuse that reports (1) frequency of drinking, (2) number of drinks consumed on a typical drinking day, and (3) frequency of binge-drinking. Each AUDIT-C item is scored from 0 to 4 , resulting in a total score ranging from 0 to 12 . According to the Spanish validation 
study, scores of 5 or higher in men and 4 or higher in women are considered the best cutoff points to detect alcohol abuse in Spanish university students (sensitivity: men $=91 \%$, women $=86 \%$; specificity: men $=84 \%$, women $=88 \%$ ) [7]. Overall, the AUDIT-C is a valid and reliable tool to identify alcohol abuse in Spanish higher education students (Cronbach's alpha $=0.75$, AUC-ROC $=0.941$ for men, 0.945 for women) [7].

\subsubsection{Drug Consumption}

Students noted their illegal drug consumption in the last six months on a list of the most-consumed illicit drugs in Spanish adults, which included cannabis, cocaine, designer drugs (MDMA-ecstasy, GHB-liquid ecstasy), amphetamines/speed, hallucinogens (LSD, ketamine, psilocybin/magic mushrooms), opioids (including heroin), legal highs, and codeine [44,45]. Participants were asked to rate whether they had consumed each drug: (0) never consumed; (1) once or twice in life but not in the last six months; (2) in the last six months; (3) in the last month; and (4) on weekends. As the study aim was to get insight about the general substance consumption of university students, participants were not asked about the frequencies of drug use.

Students were then classified in two groups on the basis of drug consumption during the last six months: non-consumers if they had not consumed any drug during the last six months, and drug consumers if they had used at least one drug during the last six months.

\subsection{Analysis}

Descriptive and inferential analyses were conducted to assess the objectives and hypotheses of the study. Prevalence rates of substance use and Odds Ratio estimates were calculated using EPIDAT 3.1. (Consellería de Sanidade, Galicia, Spain). Associations between substance use and categorical variables (i.e., sex and environmental factors) were addressed using Chi-square tests. Student $t$-test was used to explore the association between substance abuse and students' age. Logistic regression models were conducted to identify risk factors for drug consumption. Bivariate and multivariate analyses were conducted with the SPSS version 20.0 (SPSS Inc., Chicago, IL, USA). A value of $p<0.05$ was considered statistically significant.

\section{Mediation Analysis}

A Partial least squares equation modeling approach (PLS-SEM) was employed to explore the mediating role of alcohol abuse in the relationship between tobacco smoking, alcohol abuse and drug consumption. SmartPLS v. 3.2.9. (Ringle, Wende \& Becker, Bönningstedt, Germany) was used to test the structural model (Figure 1). Tobacco smoking status (non-smoker vs. current smoker) and alcohol abuse (indicators: AUDIT-C items) were entered as predictor factors, and drug consumption was entered as the dependent variable (indicators: consumption of each drug during the last six months).

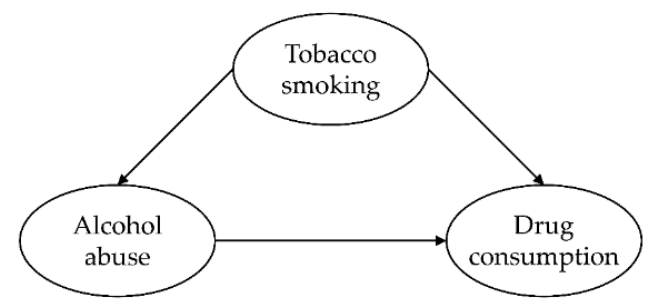

Figure 1. Conceptional model of the mediating effect of alcohol abuse in the relationship between tobacco smoking and drug consumption.

Path weighting scheme was run with a maximum of 300 iterations and a stop criterion of $1^{*} 10^{-7}$. Reliability was assessed with internal consistency (Cronbach's alpha $>0.7$ ) and composite reliability $(>0.6)$. Indicators with outer loadings $<0.4$ were removed [46]. An average variance extracted (AVE) of $>0.5$ was considered as indicative of good convergent validity. The heterotrait-monotrait ratio of 
correlations (HTMT) was used to establish discriminant validity (HTMT < 0.9) [47]. A total of 5000 bootstrap subsamples were used to test the hypotheses. Both direct, indirect and total effects of tobacco smoking and alcohol abuse on drug consumption were estimated. Variance accounted for (VAF) values of $>0.2$ and $>0.8$ demonstrated partial and full mediation, respectively [46].

\section{Results}

Of the 17,032 students who were invited to participate in the study, 584 (3.4\%) completed the questionnaire, but 34 responses were discarded (i.e., incomplete or invalid). Thus, a total sample of 550 students $(94.2 \%)$ were included in the analyses $(\mathrm{M}=23.1$ years, $\mathrm{SD}=5.4 ;$ men $=28.9 \%)$. Environmental and academic characteristics of the sample are shown in Table 1.

Table 1. Environmental and academic characteristics of the sample $(n=550)$.

\begin{tabular}{ccc}
\hline Factors & $n$ & $\%$ \\
\hline House Arrangement & 220 & 40.0 \\
Lives with Family & 40 & 7.3 \\
Lives Alone & 57 & 10.4 \\
Lives with Partner & 40 & 7.3 \\
Other & 193 & 35.1 \\
Lives with Other Students & & \\
Living Area & 302 & 54.9 \\
Urban & 141 & 25.6 \\
Suburban & 107 & 19.5 \\
Rural & & \\
Student Status & 447 & 81.3 \\
Bachelor Student & 55 & 10.0 \\
Master's Student & 48 & 8.7 \\
PhD Student & & \\
Field of Study & 28 & 5.1 \\
Arts and Humanities & 142 & 25.8 \\
Engineering and Architecture & 103 & 18.7 \\
Health Sciences & 76 & 13.8 \\
Sciences & 201 & 36.5 \\
\hline Social and Legal Sciences & &
\end{tabular}

\subsection{Prevalence of Substance Abuse and Associated Factors}

As displayed in Table 2, 74.4\% of students had never smoked, and 10.5\% were ex-smokers. Up to $22.5 \%$ of the sample showed alcohol use issues. The most consumed drug was cannabis; as many as $43.6 \%$ of the students had consumed cannabis at least once or twice in their lives, and $14.9 \%$ of the students had consumed cannabis during the last six months. Prevalence of use of at least one drug during the last six months was $17.3 \%$. The number of drugs used by those students who consumed illegal drugs during the last six months ranged from 1 to $7(\mathrm{M}=1.3, \mathrm{SD}=0.9)$. Detailed information regarding AUDIT-C is shown in Table A1 (Appendix A).

Table 2. Prevalence of substance use in students $(n=550)$.

\begin{tabular}{ccc}
\hline Substance Abuse. & $\boldsymbol{n}$ & $\boldsymbol{\%}$ \\
\hline Tobacco Smoking & & \\
Never Smoked & 409 & 74.4 \\
Ex-smoker & 58 & 10.5 \\
Current Smoker $(<15 \mathrm{c} / \mathrm{d})$ & 72 & 13.1 \\
Current Smoker $(\geq 15 \mathrm{c} / \mathrm{d})$ & 11 & 2.0 \\
\hline
\end{tabular}


Table 2. Cont.

\begin{tabular}{|c|c|c|}
\hline Substance Abuse. & $n$ & $\%$ \\
\hline Non-smoker & 467 & 84.9 \\
\hline Current Smoker & 83 & 15.1 \\
\hline Alcohol Abuse & & \\
\hline Low-risk Drinker & 426 & 77.5 \\
\hline Alcohol Abuse & 124 & 22.5 \\
\hline \multicolumn{3}{|l|}{ Drug Consumption } \\
\hline \multicolumn{3}{|l|}{ Cannabis } \\
\hline Never Consumed & 310 & 56.4 \\
\hline Once or Twice in Life (but not in the Last Six Months) & 158 & 28.7 \\
\hline In the Last Six Months & 31 & 5.6 \\
\hline In the Last Month & 36 & 6.5 \\
\hline On Weekends & 15 & 2.7 \\
\hline \multicolumn{3}{|l|}{ Cocaine } \\
\hline Never Consumed & 514 & 93.5 \\
\hline Once or Twice in Life (but not in the Last Six Months) & 25 & 4.5 \\
\hline In the Last Six Months & 5 & 0.9 \\
\hline In the Last Month & 5 & 0.9 \\
\hline On Weekends & 1 & 0.2 \\
\hline \multicolumn{3}{|l|}{ Designer Drugs } \\
\hline Never Consumed & 512 & 93.1 \\
\hline Once or Twice in Life (but not in the Last Six Months) & 29 & 5.3 \\
\hline In the Last Six Months & 4 & 0.7 \\
\hline In the Last Month & 4 & 0.7 \\
\hline On Weekends & 1 & 0.2 \\
\hline \multicolumn{3}{|l|}{ Amphetamines/Speed } \\
\hline Never Consumed & 529 & 96.2 \\
\hline Once or Twice in Life (but not in the Last Six Months) & 14 & 2.5 \\
\hline In the Last Six Months & 4 & 0.7 \\
\hline In the Last Month & 3 & 0.5 \\
\hline On Weekends & 0 & 0.0 \\
\hline \multicolumn{3}{|l|}{ Hallucinogens } \\
\hline Never Consumed & 524 & 95.3 \\
\hline Once or Twice in Life (but not in the Last Six Months) & 20 & 3.6 \\
\hline In the Last Six Months & 4 & 0.7 \\
\hline In the Last Month & 2 & 0.4 \\
\hline On Weekends & 0 & 0.0 \\
\hline \multicolumn{3}{|l|}{ Opioids } \\
\hline Never Consumed & 546 & 99.3 \\
\hline Once or Twice in Life (but not in the Last Six Months) & 3 & 0.5 \\
\hline In the Last Six Months & 0 & 0.0 \\
\hline In the Last Month & 0 & 0.0 \\
\hline On Weekends & 1 & 0.2 \\
\hline \multicolumn{3}{|l|}{ Legal Highs } \\
\hline Never Consumed & 546 & 99.3 \\
\hline Once or Twice in Life (but not in the Last Six Months) & 1 & 0.2 \\
\hline In the Last Six Months & 0 & 0.0 \\
\hline In the Last Month & 1 & 0.2 \\
\hline On Weekends & 2 & 0.4 \\
\hline \multicolumn{3}{|l|}{ Codeine } \\
\hline Never Consumed & 520 & 94.5 \\
\hline Once or Twice in Life (but not in the Last Six Months) & 23 & 4.2 \\
\hline In the Last Six Months & 4 & 0.7 \\
\hline In the Last Month & 2 & 0.4 \\
\hline On Weekends & 1 & 0.2 \\
\hline Non-Consumer & 455 & 82.7 \\
\hline Drug Consumer & 95 & 17.3 \\
\hline
\end{tabular}


Regarding risk factors for substance use (Table 3), age was associated with tobacco smoking, but not with alcohol or drug consumption. Male students reported more drug consumption than female students, and those students who lived with other students showed more alcohol and drug consumption than those students who had other living arrangements (i.e., living with family/partner or alone). Living area and academic factors were not associated with substance use.

Table 3. Sociodemographic and environmental risk factors for substance abuse $(n=550)$.

\begin{tabular}{|c|c|c|c|c|c|c|}
\hline Factors & $\begin{array}{l}\text { Current } \\
\text { Smoker }\end{array}$ & $\begin{array}{c}p \\
\text { Value }\end{array}$ & $\begin{array}{l}\text { Alcohol } \\
\text { Abuse }\end{array}$ & $\begin{array}{c}p \\
\text { Value }\end{array}$ & $\begin{array}{c}\text { Drug } \\
\text { Consumption }\end{array}$ & $\begin{array}{c}p \\
\text { Value }\end{array}$ \\
\hline Age (M (SD)) & $24.2(6.7)$ & 0.039 & $22.5(4.0)$ & 0.230 & $22.9(6.0)$ & 0.726 \\
\hline $\operatorname{Sex}(N(\%))$ & & 0.792 & & 0.067 & & 0.002 \\
\hline Men & $25(15.7)$ & & 44 (27.7) & & $40(25.2)$ & \\
\hline Women & $58(14.8)$ & & $80(20.5)$ & & $55(14.1)$ & \\
\hline Living Arrangement (N (\%)) & & 0.473 & & 0.025 & & 0.003 \\
\hline Lives with Other Students & $32(16.6)$ & & $54(28.0)$ & & $46(23.8)$ & \\
\hline $\begin{array}{c}\text { Lives with } \\
\text { Family/Partner/Alone }\end{array}$ & $51(14.3)$ & & $70(19.6)$ & & $49(13.7)$ & \\
\hline Living Area $(\mathrm{N}(\%))$ & & 0.115 & & 0.675 & & 0.252 \\
\hline Urban & $49(16.2)$ & & $71(23.5)$ & & $56(18.5)$ & \\
\hline Suburban & $14(9.9)$ & & 28 (19.9) & & $18(12.8)$ & \\
\hline Rural & 20 (18.7) & & $25(23.4)$ & & 21 (19.6) & \\
\hline Student Status (N (\%)) & & 0.540 & & 0.213 & & 0.082 \\
\hline Bachelor Student & $68(15.2)$ & & $101(22.6)$ & & $80(17.9)$ & \\
\hline Master's Student & $10(18.2)$ & & $16(29.1)$ & & $12(21.8)$ & \\
\hline PhD Student & $5(10.4)$ & & $7(14.6)$ & & $3(6.2)$ & \\
\hline Field of Study (N (\%)) & & 0.891 & & 0.277 & & 0.366 \\
\hline Arts and Humanities & $4(14.3)$ & & $3(10.7)$ & & $4(14.3)$ & \\
\hline Engineering and Architecture & $18(12.7)$ & & $29(20.4)$ & & $38(26.8)$ & \\
\hline Health Sciences & $17(16.5)$ & & $16(15.5)$ & & $21(20.4)$ & \\
\hline Sciences & $11(14.5)$ & & $8(10.5)$ & & $13(17.1)$ & \\
\hline Social and Legal Sciences & $33(16.4)$ & & $39(19.4)$ & & $48(23.9)$ & \\
\hline \multicolumn{7}{|l|}{ Substance Abuse (N (\%)) } \\
\hline Current Smoker & - & - & $45(54.2)$ & $<0.001$ & $40(48.2)$ & $<0.001$ \\
\hline Non-Smoker & - & - & 79 (16.9) & & $55(11.8)$ & \\
\hline Alcohol Abuse & $45(36.3)$ & $<0.001$ & - & - & $46(37.1)$ & $<0.001$ \\
\hline Low-Risk Drinker & $38(8.9)$ & & - & - & $49(11.5)$ & \\
\hline Drug Consumption & $40(42.1)$ & $<0.001$ & $46(48.4)$ & $<0.001$ & - & - \\
\hline Non-Consumer & $43(9.5)$ & & 78 (17.1) & & - & - \\
\hline
\end{tabular}

Tobacco smoking and alcohol abuse both predicted drug consumption independently. Students who smoked tobacco cigarettes were almost six times more likely to present alcohol abuse $(\mathrm{OR}=5.8$, $95 \% \mathrm{CI}=3.6-9.5)$ and seven times more likely to consume drugs ( $\mathrm{OR}=7.0,95 \% \mathrm{CI}=4.2-11.7)$. Additionally, those students with alcohol abuse issues were four times more likely to consume drugs $(\mathrm{OR}=4.6,95 \% \mathrm{CI}=2.8-7.3)$.

According to the multivariate analysis, predictors for drug consumption were tobacco smoking, alcohol abuse, male sex, and living with other students (Table 4).

Table 4. Logistic multivariate analysis to identify multifactorial predictors for drug consumption.

\begin{tabular}{ccccc}
\hline Variable & B & SE & $p$ Value & OR (95\% CI) \\
\hline Tobacco Smoking & 1.667 & 0.289 & $<0.001$ & $5.3(3.0-9.3)$ \\
Alcohol Abuse & 0.989 & 0.269 & $<0.001$ & $2.7(1.6-4.6)$ \\
Male Sex & 0.713 & 0.259 & 0.006 & $2.0(1.2-3.4)$ \\
Lives with Other Students & 0.601 & 0.253 & 0.017 & $1.8(1.1-3.0)$ \\
\hline B = B coefficient value; SE = standard error; OR = odds ratio; 95\% CI = 95\% confidence interval.
\end{tabular}




\subsection{Mediating Analysis}

Codeine, legal highs, and opioids were excluded of the analysis as they did not meet the threshold limit of reliability and validity [46]. The final model of the analysis had two constructs with reflective measurements (alcohol abuse and drug consumption) and one binary construct as predictor (tobacco smoking status) (Figure 2). As Table 5 illustrates, Cronbach's alpha, composite reliability, and AVE values met the recommended criteria. HTMT values were all below $0.9(0.487-0.506)$.

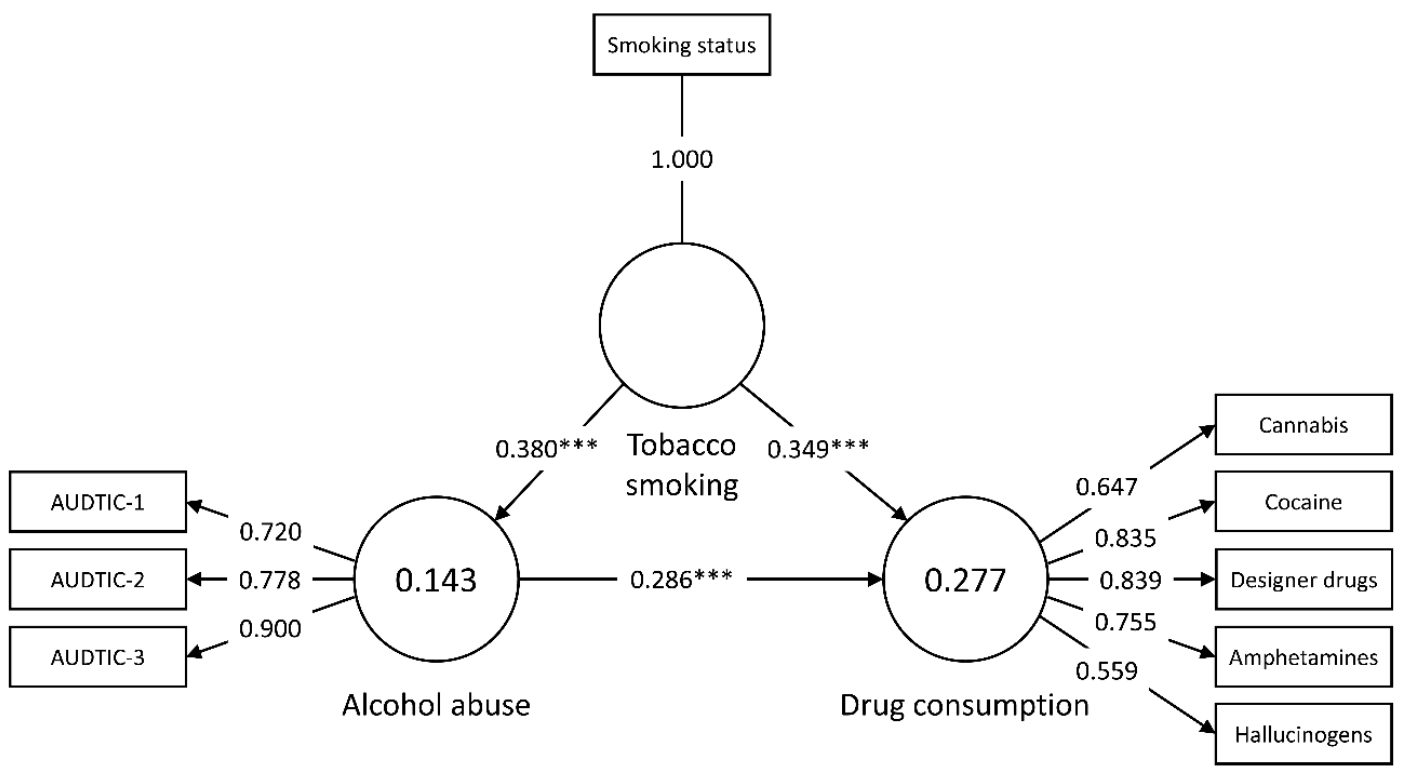

Figure 2. Path analysis of the mediating relationship. ${ }^{* * *} p<0.001$.

Table 5. Assessment of the measurement model (reflective).

\begin{tabular}{cccccc}
\hline Construct & Items & LV & $\alpha$ & CR & AVE \\
\hline Alcohol Abuse & & & 0.756 & 0.844 & 0.645 \\
& AUDITC-1 & 0.720 & & & \\
& AUDITC-2 & 0.778 & & & \\
AUDITC-3 & 0.900 & & & \\
& & & 0.786 & 0.852 & 0.541 \\
& Cannabis & 0.647 & & & \\
& Cocaine & 0.835 & & & \\
& Designer Drugs & 0.839 & & & \\
& Amphetamines & 0.755 & & & \\
& Hallucinogens & 0.559 & & & \\
& &
\end{tabular}

$\mathrm{LV}=$ outer loading value; $\alpha=$ Cronbach's alpha; $\mathrm{CR}=$ composite reliability; $\mathrm{AVE}=$ average variance extracted.

The outcomes of hypotheses testing are presented in Table 6 . The bootstrapping results revealed that there was a direct effect of both tobacco smoking and alcohol abuse on drug consumption during the last six months, while tobacco smoking also had a direct effect on alcohol abuse. The results of the mediating analysis supported the significant and partial effect of alcohol abuse as a mediator in the relationship between tobacco smoking and drug consumption ( $\mathrm{VAF}=24.0 \%)$. 
Table 6. Hypotheses testing for direct and mediating relationships.

\begin{tabular}{cccccc}
\hline Hypotheses & \multicolumn{2}{c}{ Effects } & $\boldsymbol{t}$-Value & $\boldsymbol{p}$ Value & Supported \\
\hline$(\mathrm{H} 1) \mathrm{TS} \rightarrow \mathrm{DC}$ & Path coeff. & 0.349 & 6.335 & $<0.001$ & Yes \\
$\left(\mathrm{H}_{2}\right) \mathrm{TS} \rightarrow \mathrm{AA}$ & Path coeff. & 0.380 & 8.146 & $<0.001$ & Yes \\
$\left(\mathrm{H}_{3}\right) \mathrm{AA} \rightarrow \mathrm{DC}$ & Path coeff. & 0.286 & 5.035 & $<0.001$ & Yes \\
$\left(\mathrm{H}_{4}\right) \mathrm{TS} \rightarrow \mathrm{AA} \rightarrow \mathrm{DC}$ & Direct & 0.349 & 6.335 & $<0.001$ & Yes \\
& Indirect & 0.109 & 4.168 & $<0.001$ & \\
& Total & 0.458 & 10.491 & $<0.001$ & \\
\hline
\end{tabular}

TS = tobacco smoking; $\mathrm{AA}=$ alcohol abuse; $\mathrm{DU}=$ drug consumption.

\section{Discussion}

The main findings of this study were as follows: (1) prevalence of substance use in the sample is high, especially considering that up to $22.5 \%$ of the participants reported alcohol abuse and that almost half of the students had used cannabis at least once in their life; (2) men and students who lived with other students were more likely to consume illegal drugs; (3) tobacco smoking and risky alcohol behavior were associated with illegal drug consumption, both in the bivariate and the multivariate analyses; and (4) alcohol had a mediating effect in the relationship between tobacco smoking and illegal drug consumption in university students.

\subsection{Prevalence of Substance Use}

Rates of substance abuse in this sample are high but similar to those found in previous research on Spanish university students. Up to $15 \%$ of students were currently smokers at the time of this study, which is less than reported by other Spanish authors during the past decade [4-6,29]. However, these findings are in line with some recent published works on Spanish university students that indicate that tobacco consumption may be decreasing in younger university students [2,48].

As expected, alcohol was the most consumed substance, as $84.9 \%$ of students reported consuming alcohol at least once a month, and $54.2 \%$ reported regular consumption according to the AUDIT-C (i.e., at least 2-4 times a month). Alcohol use is highly prevalent among university students, both in Spain and in other European and American regions [2,16,17,28,29,38,49-51]. New and complex patterns of alcohol abuse exist among university students, and these problems represent a major public health concern $[1,9,20,52,53]$.

Our findings regarding illegal drug use confirm that cannabis is the most consumed illegal drug among university students (43.6\%). Almost half of students had used cannabis at least once or twice in their life, and $14.8 \%$ reported cannabis consumption during the last six months. These rates are worrying but in line with previous research on cannabis use in university students [1-6,8]. Studies regarding other illegal drugs apart from cannabis use are scarce, as most of them solely explore cannabis consumption $[8,54]$. However, hard drugs have pervasive and negative effects on mental health, behavior, and further drug use problems [55], and therefore should be further addressed as they seem to be prevalent in this population.

\subsection{Individual and Environmental Risk Factors for Tobacco Smoking, Alcohol Abuse and Illegal Drug Consumption}

Male and female students reported similar rates of tobacco smoking and alcohol abuse, while men were more likely to engage in illegal drug consumption. These findings are consistent with previous research that systematically reports male sex as a factor risk for the use of cannabis and other drugs $[8,28,29]$. Men are more likely to simultaneously co-use cannabis with alcohol and tobacco as well [56]. The well-explored association between impulsivity traits and substance consumption $[55,57,58]$ could contribute to explain why male students use drugs more than women, as impulsivity disorders are more prevalent among men [59,60]. 
Findings from this study confirm that environmental factors have a great effect on substance abuse. Living with other students was a risk factor for alcohol abuse and drug consumption, even after multivariate analysis, which is in line with most studies regarding substance abuse in university students $[1,6,8,28,29,51,61]$. Several authors propose that family proximity plays a protective role in substance abuse among adolescents and higher education students [29,62-64]. This protective factor could contribute to explaining why students who live away from the family home are more likely to engage in risky alcohol behaviors and illicit drug use. However, this shielding effect could not be as effective in heavy drinking episodes or binge drinking in Spanish young adults [65], and future studies should explore the longitudinal effects of living away from the family home on risky alcohol behavior among university students.

Apart from the potential protective role that parental monitoring may play, interaction with peers contribute to explaining why living with other students is associated with substance abuse. Research has demonstrated that both peers' substance use and peers' positive attitude toward drugs strongly associate with tobacco smoking, alcohol abuse, and drug consumption among university students [26]. As a matter of fact, the fear of being socially alienated and excluded is one of the factors that relates the most with alcohol abuse in this population $[62,66]$.

\subsection{Relationship between Tobacco Smoking, Alcohol Abuse and Illegal Drug Consumption}

Both tobacco smoking and alcohol abuse significantly predicted illegal drug consumption in university students, even after controlling for sex and living arrangement. Tobacco smoking was the strongest predictor for illegal drug consumption, both in the multivariate analysis and in the PLS-SEM mediating analysis. According to the mediating analysis, alcohol abuse alone had both a direct and indirect influence on drug consumption among university students. To the best of our knowledge, this analysis had not been explored before, but this finding is consistent with previous research in the relationship between tobacco smoking, alcohol abuse and drug consumption $[28,38,39,67,68]$.

Findings from the mediating analysis could be explained by the Gateway Hypothesis, which describes how use of legal and easily accessible drugs (typically tobacco or alcohol) precedes use of harder and more addictive drugs, such as marijuana, cocaine and other illegal drugs [69]. This sequence of progression of drug consumption has been extensively explored and is well-defined, especially in Western populations [69,70]. Although this hypothesis has been discussed and is not without controversy, research supports that the gateway sequence (i.e., tobacco/alcohol use precedes the use of cannabis, which in turn precedes the use of other illegal drugs) is followed by the majority of illicit drug users [69-71]. Numerous retrospective and longitudinal studies have found a positive association between early exposure to cigarette smoking and alcohol use and later use of marijuana, cocaine, non-medical use of prescription drugs and other illegal drugs in humans [2,33,35,72-75].

Regarding findings from longitudinal studies, Nkansah-Amankra and Minello followed 14,738 American adolescents over 14 years and gathered data about their legal and illegal substance use at baseline (early adolescence), adolescence (12-18 years), and early (19-23 years) and young adulthood (24-33 years), considering tobacco, alcohol, and marijuana as "gateway" drugs [72,73]. Overall, they found that early use of cigarettes and alcohol increased the likelihood of using marijuana and other illegal drugs during older adolescence and early and young adulthood [72,73]. However, early use of marijuana and other illicit drugs greatly increased the risk of using harder drugs in adults older than 23 years [72]. Given that participants in our study were an average of 23 years, our findings could reflect an early exposure to "gateway" substances (i.e., tobacco and alcohol) during early or older adolescence, though this relationship cannot be established as this study is not longitudinal in nature.

The outcomes of this study may be useful for expanding on the relationship between individual and environmental factors and substance abuse, and for assessing the mediating effect of alcohol in the relationship between tobacco smoking and drug consumption. This finding is particularly relevant because alcohol abuse was the most prevalent risky behavior in the sample. Most university students consume alcohol regularly as a leisure and social activity, and new patterns of alcohol abuse are present 
in this population, such as binge drinking, weekend drinking and alone drinking $[17,20,52,53,56]$. While both tobacco and alcohol are usually proposed as the primary drivers of the gateway hypothesis or "gateway" drugs, [69,70], the mediating effect of alcohol abuse in the relationship between tobacco smoking and illegal drug consumption suggests that alcohol may play a more complex role in this hypothesis, or even represent the "gateway" drug leading to the use of other licit and/or illicit drugs [76].

Overall, risky alcohol consumption behavior has an adverse effect across psychosocial wellbeing, academic performance, quality of life, and general health [9-14,41,77,78], but also contributes to increasing the risk of drug abuse in students who already smoke cigarettes. This is of utmost importance because most adolescents and young adults believe that intermittent tobacco smoking causes little or no harm, and therefore are at more risk of engaging in risky and unhealthy behaviors [79].

Prevention programs aimed to decrease the prevalence of tobacco smoking, alcohol misuse or illegal drug consumption in university students should especially focus on students who are in a more vulnerable situation. Due to the complex interrelation between the individual and environmental factors that altogether contribute to substance abuse, a multidisciplinary approach should be used. It is necessary for health professionals and academic institutions to design collaborative prevention and intervention strategies. Given the relationship between environmental factors and substance abuse, and the impact of substance abuse on daily participation, behavior and performance, occupational therapists and psychologists could significantly contribute to the multidisciplinary team in order to promote healthy lifestyles in university students [80].

\subsection{Limitations and Future Research Directions}

This study is not without limitations. Data collection relied exclusively on self-reported questionnaires, which may introduce bias. The frequency of illegal drug use (i.e., monthly, weekly or daily) was not established, and should be comprehensively explored in future studies. Another limitation is that all participants came from one university in Northwest Spain and participation rate was low. It may be possible that those students with higher illicit drug consumption may have been less likely to respond as by doing so, they would be disclosing illegal behavior. Questionnaires were responded to anonymously and efforts were made to ensure anonymity of the participants (i.e., age was registered in years and not as birth date) to try and prevent this potential bias. Additionally, the sample included participants from different geographical settings, sociodemographics, and academic backgrounds, and findings are similar to other studies conducted with Spanish students from other regions, so it can be assumed that conclusions from this study regarding the mediating role of alcohol abuse in the relationship between tobacco smoking and illegal drug consumption can be generalized to other university students. Finally, cross-sectional studies cannot establish causality between individual and environmental factors and substance consumption.

\section{Conclusions}

Tobacco smoking, alcohol abuse, and illegal drug consumption are frequent problems in Spanish university students. Sex and living with other students interrelate with poly-substance use to predict alcohol and drug consumption. Findings from this study reveal that alcohol abuse has a mediating effect in the relationship between tobacco smoking and drug consumption in university students, and therefore risky alcohol behaviors should be promptly assessed in this population. Due to its consequences on quality of life, mental health, and academic performance, a multidisciplinary approach should be implemented in academic institutions to prevent and treat substance abuse.

Author Contributions: Conceptualization, L.D.-L., R.M.-M., A.V.-P., J.-M.C.-V., B.G.-G., M.-Á.T.-V. and S.S.-d.-R.; methodology, L.D.-L. and R.M.-M.; validation, L.D.-L., R.M.-M., A.V.-P., J.-M.C.-V., B.G.-G., M.-Á.T.-V. and S.S.-d.-R.; formal analysis, L.D.-L. and R.M.-M.; investigation, L.D.-L., R.M.-M., A.V.-P., J.-M.C.-V., B.G.-G., M.-Á.T.-V. and S.S.-d.-R.; resources, L.D.-L., R.M.-M. and S.S.-d.-R.; data curation, L.D.-L. and R.M.-M.; writing一original draft preparation, L.D.-L. and R.M.-M.; writing-review and editing, L.D.-L., R.M.-M. and S.S.-d.-R.; supervision, 
L.D.-L., R.M.-M. and S.S.-d.-R.; project administration, L.D.-L., R.M.-M. and S.S.-d.-R. All authors have read and agreed to the published version of the manuscript.

Funding: This research received no external funding.

Acknowledgments: The authors want to thank the University of A Coruña Administration and Vicerreitoría do Campus de Ferrol e Responsabilidade Social, which contributed to data collection. The authors would like to thank the anonymous referees for their thoughtful comments and efforts towards improving our manuscript.

Conflicts of Interest: The authors declare no conflict of interest.

\section{Appendix A}

Table A1. AUDIT-C $(n=550)$.

\begin{tabular}{ccc}
\hline Audlt-C & $n$ & $\%$ \\
\hline How Often Do You Have a Drink Containing Alcohol? & & \\
Never & 83 & 15.1 \\
Monthly or Less & 169 & 30.7 \\
$2-4$ times a month & 232 & 42.2 \\
$2-3$ times a week & 55 & 10.0 \\
4 or more times a week & 11 & 2.0 \\
How Many Standard Drinks Containing Alcohol Do You Have on a Typical Day? & 383 & 69.6 \\
3 or 4 & 116 & 21.1 \\
5 or 6 & 43 & 7.8 \\
7 or 9 & 5 & 0.9 \\
10 or more & 3 & 0.5 \\
Never & & \\
Less than Monthly & 335 & 60.9 \\
Monthly & 131 & 23.8 \\
Weekly & 55 & 10.0 \\
Daily or Almost Daily & 28 & 5.1 \\
& & 0.2 \\
\hline
\end{tabular}

\section{References}

1. Páramo, M.F.; Cadaveira, F.; Tinajero, C.; Rodríguez, M.S. Binge Drinking, Cannabis Co-Consumption and Academic Achievement in First Year University Students in Spain: Academic Adjustment as a Mediator. Int. J. Environ. Res. Public Health 2020, 17, 542. [CrossRef]

2. Busto Miramontes, A.; Moure-Rodríguez, L.; Díaz-Geada, A.; Rodríguez-Holguín, S.; Corral, M.; Cadaveira, F.; Caamaño-Isorna, F. Heavy Drinking and Non-Medical Use of Prescription Drugs among University Students: A 9-Year Follow-Up. Int. J. Environ. Res. Public Health 2019, 16, 2939. [CrossRef]

3. Jiménez-Mejías, E.; Medina-García, M.A.; Martínez-Ruiz, V.; Pulido-Manzanero, J.; Fernández-Villa, T. Drug use and involvement in risky driving styles in a sample of university students. The uniHcos project. Gac. Sanit. 2015, 29, 4-9. [CrossRef]

4. Roncero, C.; Rodríguez-Cintas, L.; Egido, A.; Barral, C.; Pérez-Pazos, J.; Collazos, F.; Grau-López, L.; Casas, M. The influence of medical student gender and drug use on the detection of addiction in patients. J. Addict. Dis. 2014, 33, 277-288. [CrossRef] [PubMed]

5. Varela-Mato, V.; Cancela, J.M.; Ayan, C.; Martín, V.; Molina, A. Lifestyle and Health among Spanish University Students: Differences by Gender and Academic Discipline. Int. J. Environ. Res. Public Health 2012, 9, 2728-2741. [CrossRef]

6. Caamaño-Isorna, F.; Mota, N.; Creggo, A.; Corral, M.; Rodríguez-Holguín, S.; Cadaveira, F. Consumption of medicines, alcohol, tobacco and cannabis among university students: A 2-year follow-up. Int. J. Public Health 2011, 56, 247-252. [CrossRef] [PubMed]

7. García Carretero, M.A.; Novalbos Ruiz, J.P.; Martínez Delgado, J.M.; O’Ferrall González, C. Validation of the Alcohol Use Disorders Identification Test in university students: AUDIT and AUDIT-C. Adicciones 2016, 28, 194-204. [CrossRef] [PubMed] 
8. De la Torre, J.A.; Fernández-Villa, T.; Molina, A.J.; Amezcua-Prieto, C.; Mateos, R.; Cancela, J.M.; Delgado-Rodríguez, M.; Ortíz-Moncada, R.; Alguacil, J.; Almaraz, A.; et al. Drug use, family support and related factors in university students. A cross-sectional study based on the uniHcos Project data. Gac. Sanit. 2019, 33, 141-147. [CrossRef] [PubMed]

9. Parada, M.; Corral, M.; Mota, N.; Crego, A.; Rodríguez-Holguín, S.; Cadaveira, F. Executive functioning and alcohol binge drinking in university students. Addict. Behav. 2012, 37, 167-172. [CrossRef] [PubMed]

10. Gil-Hernandez, S.; Mateos, P.; Porras, C.; Garcia-Gomez, R.; Navarro, E.; Garcia-Moreno, L.M. Alcohol Binge Drinking and Executive Functioning during Adolescent Brain Development. Front. Psychol. 2017, 8, 1638. [CrossRef]

11. Martinez, J.A.; Roth, M.G.; Johnson, D.N.; Jones, J.A. How Robustly Does Cannabis Use Associate to College Grades? Findings from Two Cohorts. J. Drug Educ. 2015, 45, 56-67. [PubMed]

12. Piazza-Gardner, A.K.; Merianos, A.L.; Barry, A.E. Assessing Drinking and Academic Performance among a Nationally Representative Sample of College Students. J. Drug Issues 2016, 46, 347-353. [CrossRef]

13. Tembo, C.; Burns, S.; Kalembo, F. The association between levels of alcohol consumption and mental health problems and academic performance among young university students. PLoS ONE 2017, 12, e0178142. [CrossRef] [PubMed]

14. Patte, K.A.; Qian, W.; Leatherdale, S.T. Marijuana and Alcohol Use as Predictors of Academic Achievement: A Longitudinal Analysis Among Youth in the COMPASS Study. J. Sch. Health 2017, 87, 310-318. [CrossRef]

15. Hernández-Serrano, O.; Gras, M.E.; Font-Mayolas, S. Concurrent and Simultaneous Use of Cannabis and Tobacco and Its Relationship with Academic Achievement amongst University Students. Behav. Sci. 2018, 8, 31. [CrossRef]

16. El Ansari, W.; Ssewanyana, D.; Stock, C. Behavioral Health Risk Profiles of Undergraduate University Students in England, Wales, and Northern Ireland: A Cluster Analysis. Front. Public Health 2018, 7, 120. [CrossRef]

17. Mason, W.A.; Stevens, A.L.; Fleming, C.B. A systematic review of research on adolescent solitary alcohol and marijuana use in the United States. Addiction 2020, 115, 19-31. [CrossRef]

18. Morin, J.G.; Afzali, M.H.; Bourque, J.; Stewart, S.H.; Séguin, J.R.; O’Leary-Barrett, M.; Conrod, P.J. A Population-Based Analysis of the Relationship between Substance Use and Adolescent Cognitive Development. Am. J. Psychiatry 2019, 176, 98-106. [CrossRef]

19. Baiden, P.; Mengo, C.; Boateng, G.O.; Small, E. Investigating the association between age at first alcohol use and suicidal ideation among high school students: Evidence from the youth risk behavior surveillance system. J. Affect. Disord. 2019, 242, 60-67. [CrossRef]

20. Dormal, V.; Bremhorst, V.; Lannoy, S.; Lorant, V.; Luquiens, A.; Maurage, P. Binge drinking is associated with reduced quality of life in young students: A pan-European study. Drug Alcohol Depend. 2018, 193, 48-54. [CrossRef]

21. Buckner, J.D.; Lewis, E.M.; Shah, S.M.; Walukevich, K.A. Risky sexual behavior among cannabis users: The role of protective behavioral strategies. Addict. Behav. 2018, 81, 50-54. [CrossRef] [PubMed]

22. Moure-Rodríguez, L.; Doallo, S.; Juan-Salvadores, P.; Corral, M.; Cadaveira, F.; Caamaño-Isorna, F. Heavy episodic drinking, cannabis use and unsafe sex among university students. Gac. Sanit. 2016, 30, 438-443. [CrossRef] [PubMed]

23. Credé, M.; Niehorster, S. Adjustment to college as measured by the Student Adaptation to College Questionnaire: A quantitative review of its structure and relationships with correlates and consequences. Educ. Psychol. Rev. 2012, 24, 133-165. [CrossRef]

24. Arnett, J.J. College students as emerging adults: The developmental implications of the college context. Emerg. Adulthood 2016, 4, 2019-2222. [CrossRef]

25. Merrill, J.E.; Carey, K.B. Drinking over the lifespan focus on college ages. Alcohol Res. 2016, 38, $103-114$.

26. Taremian, F.; Yaghubi, H.; Pairavi, H.; Hosseini, S.R.; Zafar, M.; Moloodi, R. Risk and protective factors for substance use among Iranian university students: A national study. Subst. Abuse Treat. Prev. Policy 2018, 13, 46. [CrossRef]

27. Shehnaz, S.I.; Agarwal, A.K.; Khan, N. A systematic review of self-medication practices among adolescents. J. Adolesc. Health 2014, 55, 467-483. [CrossRef]

28. Rogowska, A. The Relationship between Demographic Variables and Substance Use in Undergraduates. Int. J. Ment. Health Addict. 2019, 17, 1550-1563. [CrossRef] 
29. Molina, A.J.; Varela, V.; Fernández, T.; Martín, V.; Ayán, C.; Cancela, J.M. Unhealthy habits and practice of physical activity in Spanish college students: The role of gender, academic profile and living situation. Adicciones 2012, 24, 319-327. [CrossRef]

30. Cobo-Cuenca, A.I.; Garrido-Miguel, M.; Soriano-Cano, A.; Ferri-Morales, A.; Martínez-Vizcaíno, V.; Martín-Espinosa, N.M. Adherence to the Mediterranean Diet and Its Association with Body Composition and Physical Fitness in Spanish University Students. Nutrients 2019, 11, 2830. [CrossRef]

31. Tsitsimpikou, C.; Tsarouhas, K.; Vasilaki, F.; Papalexis, P.; Dryllis, G.; Choursalas, A.; Spandidos, D.A.; Tsatsakis, A.; Charvalos, E.; Bacopoulou, F. Health risk behaviors among high school and university adolescent students. Exp. Ther. Med. 2018, 16, 3433-3438. [CrossRef] [PubMed]

32. Viohl, L.; Ernst, F.; Gabrysch, J.; Petzold, M.B.; Köhler, S.; Ströhle, A.; Betzler, F. 'Higher education'—Substance use among Berlin college students. Eur. J. Neurosci. 2019, 50, 2526-2537. [CrossRef] [PubMed]

33. Moutinho, I.L.D.; Lucchetti, A.L.G.; Ezequiel, O.D.S.; Lucchetti, G. Prevalence, Incidence, and Factors Associated with Substance Use among Medical Students: A 2-Year Longitudinal Study. J. Addict. Med. 2019, 13, 295-299. [CrossRef] [PubMed]

34. De Salvia, M.A.; D’Uggento, A.M.; Aquilino, G.; Tattoli, M.; Finelli, C.; Imbrici, P.; Desaphy, J.F.; Giustino, A. Characterization of Student Drinking Behaviors at the Beginning of the First Academic Year at One University in Southern Italy. J. Addict. Nurs. 2019, 30, 193-200. [CrossRef]

35. Myers, M.G.; Doran, N.M.; Edland, S.D.; Schweizer, C.A.; Wall, T.L. Cigarette smoking initiation during college predicts future alcohol involvement: A matched-samples study. J. Stud. Alcohol Drugs 2013, 74, 909-916. [CrossRef]

36. Pilatti, A.; Caneto, F.; Garimaldi, J.A.; Vera Bdel, V.; Pautassi, R.M. Contribution of time of drinking onset and family history of alcohol problems in alcohol and drug use behaviors in Argentinean college students. Alcohol Alcohol. 2014, 49, 128-137. [CrossRef]

37. White, H.R.; Kilmer, J.R.; Fossos-Wong, N.; Hayes, K.; Sokolovsky, A.W.; Jackson, K.M. Simultaneous Alcohol and Marijuana Use Among College Students: Patterns, Correlates, Norms, and Consequences. Alcohol Clin. Exp. Res. 2019, 43, 1545-1555. [CrossRef]

38. Pilatti, A.; Godoy, J.C.; Brussino, S.A.; Pautassi, R.M. Patterns of substance use among Argentinean adolescents and analysis of the effect of age at first alcohol use on substance use behaviors. Addict. Behav. 2013, 38, 2847-2850. [CrossRef]

39. Papazisis, G.; Tsakiridis, I.; Siafis, S. Nonmedical Use of Prescription Drugs among Medical Students and the Relationship with Illicit Drug, Tobacco, and Alcohol Use. Subst. Abuse 2018, 12, 1178221818802298. [CrossRef]

40. Szalay, K.; Antal, K.; Emri, Z. Environmental, non-specific factors affecting legal and illegal drug consumption. JATES 2019, 8, 28-41.

41. Linden-Carmichael, A.N.; Mallett, K.A.; Sell, N.; Turrisi, R. Are Co-users of Alcohol and Marijuana More Willing to Experience Consequences from Drinking? A Longitudinal Examination among First-Year College Students. Alcohol Clin. Exp. Res. 2019, 43, 1567-1574. [CrossRef] [PubMed]

42. Delgado-Lobete, L.; Montes-Montes, R.; Vila-Paz, A.; Talavera-Valverde, M.-Á.; Cruz-Valiño, J.-M.; Gándara-Gafo, B.; Ávila-Álvarez, A.; Santos-del-Riego, S. Subjective Well-Being in Higher Education: Psychometric Properties of the Satisfaction with Life and Subjective Vitality Scales in Spanish University Students. Sustainability 2020, 12, 2176. [CrossRef]

43. Saunders, J.B.; Aasland, O.G.; Babor, T.F.; de la Fuente, J.R.; Grant, M. Development of the Alcohol Use Disorders Identification Test (AUDIT): WHO Collaborative Project on Early Detection of Persons with Harmful Alcohol Consumption-II. Addiction 1993, 88, 791-804. [CrossRef] [PubMed]

44. Ballesta Gómez, R.; Bilbao Acedos, I.; Tena Aguilar, M. Consejería de Igualdad y Políticas Sociales. La Población Andaluza Ante las Drogas XIII; Junta de Andalucía: Andalucia, Spain, 2016.

45. European Monitoring Centre for Drugs and Drug Addiction. European Drug Report 2019: Trends and Developments; Publications Office of the European Union: Luxembourg, Luxembourg, 2019.

46. Hair, J.F.; Hult, G.T.M.; Ringle, C.M.; Sarstedt, M. A Primer on Partial Least Squares Structural Equation Modeling (PLS-SEM), 2nd ed.; Sage: Thousand Oaks, CA, USA, 2017.

47. Henseler, J.; Ringle, C.M.; Sarstedt, M. A new criterion for assessing discriminant validity in variance-based structural equation modeling. J. Acad. Mark. Sci. 2015, 43, 115-135. [CrossRef] 
48. Font-Mayolas, S.; Sullman, M.J.M.; Gras, M.-E. Sex and Polytobacco Use among Spanish and Turkish University Students. Int. J. Environ. Res. Public Health 2019, 16, 5038. [CrossRef]

49. Moure-Rodríguez, L.; Carbia, C.; Lopez-Caneda, E.; Corral Varela, M.; Cadaveira, F.; Caamaño-Isorna, F. Trends in alcohol use among young people according to the pattern of consumption on starting university: A 9-year follow-up study. PLoS ONE 2018, 13, e0193741. [CrossRef]

50. Moure-Rodríguez, L.; Piñeiro, M.; Corral Varela, M.; Rodríguez-Holguín, S.; Cadaveira, F.; Caamaño-Isorna, F. Identifying Predictors and Prevalence of Alcohol Consumption among University Students: Nine Years of Follow-Up. PLoS ONE 2016, 11, e0165514. [CrossRef]

51. Bähler, C.; Foster, S.; Estévez, N.; Dey, M.; Gmel, G.; Mohler-Kuo, M. Changes in living arrangement, daily smoking, and risky drinking initiation among young Swiss men: A longitudinal cohort study. Public Health 2016, 140, 119-127. [CrossRef]

52. Kanny, D.; Liu, Y.; Brewer, R.D.; Lu, H. Binge drinking-United States 2011. Natl. Cent. Chronic Dis. Prev. Health Promot. 2013, 62, 77-80.

53. Lannoy, S.; Billieux, J.; Poncin, M.; Maurage, P. Binging at the campus: Motivations and impulsivity influence binge drinking profiles in university students. Psychiatry Res. 2017, 250, 146-154. [CrossRef]

54. Redonnet, B.; Chollet, A.; Fombonne, E.; Bowes, L.; Melchior, M. Tobacco, alcohol, cannabis and other illegal drug use among young adults: The socioeconomic context. Drug Alcohol Depend. 2012, 121, 231-239. [CrossRef] [PubMed]

55. Grant, J.E.; Lust, K.; Chamberlain, S.R. Hallucinogen Use is Associated with Mental Health and Addictive Problems and Impulsivity in University Students. Addict. Behav. Rep. 2019, 10, 100228. [CrossRef]

56. Lipperman-Kreda, S.; Paschall, M.J.; Robert, F.S.; Morrison, C.N. Places and social contexts associated with simultaneous use of alcohol, tobacco and marijuana among young adults. Drug Alcohol Rev. 2019, 37, 188-195. [CrossRef] [PubMed]

57. Bravo, A.J.; Pearson, M.R.; Pilatti, A.; Read, J.P.; Mezquita, L.; Ibáñez, M.I.; Ortet, G. Impulsivity-related traits, college alcohol beliefs, and alcohol outcomes: Examination of a prospective multiple mediation model among college students in Spain, Argentina, and USA. Addict. Behav. 2018, 81, 125-133. [CrossRef] [PubMed]

58. Grant, J.E.; Lust, K.; Fridgerg, D.J.; King, A.C.; Chamberlain, S.R. E-cigarette use (vaping) is associated with illicit drug use, mental health problems, and impulsivity in university students. Ann. Clin. Psychiatry 2019, 31, 27-35. [PubMed]

59. Panevska, L.S.; Zafirova-Ivanovska, B.; Vasilevska, K.; Isjanovska, R.; Kadri, H. Relationship between ADHD and depression among university students in macedonia. Mater. Sociomed. 2015, 27, 18-21. [CrossRef]

60. Ghanizadeh, A.; Salehi, A.; Moeini, S.R. Clinical Presentation of Attention-Deficit Hyperactivity Disorder Symptoms in Terms of Gender and Chronological Age. Int. J. Community Based Nurs. Midwifery 2019, 7, 241-246.

61. Yi, S.; Peltzer, K.; Pengpid, S.; Susilowati, I.H. Prevalence and associated factors of illicit drug use among university students in the association of Southeast Asian nations (ASEAN). Subst. Abuse Treat. Prev. Policy 2017, 12, 9. [CrossRef]

62. Ham, L.S.; Hope, D.A. Incorporating social anxiety into a model of college student problematic drinking. Addict. Behav. 2005, 30, 127-150. [CrossRef]

63. Kaynak, O.; Meyers, K.; Caldeira, K.M.; Vincent, K.B.; Winters, K.C.; Arria, A.M. Relationships among parental monitoring and sensation seeking on the development of substance use disorder among college students. Addict. Behav. 2013, 38, 1457-1463. [CrossRef]

64. Strunin, L.; Díaz Martínez, A.; Díaz-Martínez, L.R.; Heeren, T.; Kuranz, S.; Winter, M.; Hernández-Ávila, C.A.; Fernández-Varela, H.; Solís-Torres, C. Parental monitoring and alcohol use among Mexican students. Addict. Behav. 2013, 38, 2601-2606. [CrossRef]

65. Mota, N.; Alvarez-Gil, R.; Corral, M.; Rodríguez-Holguín, S.; Parada, M.; Creggo, A.; Caamaño-Isorna, F.; Cadaveira, F. Risky alcohol use and heavy episodic drinking among Spanish University students: A two-year follow-up. Gac. Sanit. 2010, 24, 372-377. [CrossRef]

66. Muli, N.; Laggan, B.M. Perceived determinants to alcohol consumption and misuse: A survey of university students. Perspect. Public Health 2017, 137, 326-336. [CrossRef] [PubMed]

67. Schilling, L.; Zeeb, H.; Pischke, C.; Helmer, S.; Schmidt-Pokrzywniak, A.; Reintjes, R.; Walter, U.; Girbig, M.; Krämer, A.; Icks, A.; et al. Licit and illicit substance use patterns among university students in Germany using cluster analysis. Subst. Abuse Treat. Prev. Policy 2017, 12, 44. [CrossRef] [PubMed] 
68. Rogowska, A.M. Problematic use of psychoactive substances in undergraduates: A comparison of four patterns of substance use. J. Subst. Use 2016, 21, 304-308. [CrossRef]

69. Kandel, D.; Kandel, E. The Gateway Hypothesis of substance abuse: Developmental, biological and societal perspectives. Acta Paediatr. 2015, 104, 130-137. [CrossRef] [PubMed]

70. Degenhardt, L.; Dierker, L.; Chiu, W.T.; Medina-Mora, M.E.; Neymark, Y.; Sampson, N.; Alonso, J.; Angermeyer, M.; Anthony, J.C.; Bruffaerts, R.; et al. Evaluating the drug use "gateway" theory using cross-national data: Consistency and associations of the order of initiation of drug use among participants in the WHO World Mental Health surveys. Drug Alcohol Depend. 2010, 108, 84-97. [CrossRef] [PubMed]

71. Tarter, R.E.; Vanyukov, M.; Kirisci, L.; Reynolds, M.; Clark, D.B. Predictors of marijuana use in adolescents before and after licit drug use: Examination of the gateway hypothesis. Am. J. Psychiatry 2006, 163, 2134-2140. [CrossRef] [PubMed]

72. Nkansah-Amankra, S.; Minelli, M. "Gatewayy hypothesis" and early drug use: Additional findings from tracking a population-based sample of adolescents to adulthood. Prev. Med. Rep. 2016, 4, 134-141. [CrossRef]

73. Nkansah-Amankra, S. Revisiting the Association between "Gateway Hypothesis" of Early Drug Use and Drug Use Progression: A Cohort Analysis of Peer Influences on Drug Use Progression among a Population Cohort. Subst. Use Misuse 2020, 55, 998-1007. [CrossRef]

74. Mayet, A.; Legleye, S.; Falissard, B.; Chau, N. Cannabis use stages as predictors of subsequent initiation with other illicit drugs among French adolescents: Use of a multi-state model. Addict. Behav. 2012, 37, 160-166. [CrossRef]

75. Kurti, A.N.; Keith, D.R.; Noble, A.; Priest, J.S.; Sprague, B.; Higgins, S.T. Characterizing the intersection of Co-occurring risk factors for illicit drug abuse and dependence in a U.S. nationally representative sample. Prev. Med. 2016, 92, 118-125. [CrossRef]

76. Kirby, T.; Barry, A.E. Alcohol as a gateway drug: A study of US 12th graders. J. Sch. Health 2012, 82, 371-379. [CrossRef]

77. Faílde Garrido, J.M.; Ruiz Soriano, L.; Pérez Fernández, M.R.; Lameiras Fernández, M.; Rodríguez Castro, Y. Evolution of quality of life and health-related behaviors among Spanish university students. Int. J. Health Plan. Manag. 2019, 34, e789-e801. [CrossRef] [PubMed]

78. Villarosa-Hurlocker, M.C.; Bravo, A.J.; Pearson, M.R. The Relationship between Social Anxiety and Alcohol and Marijuana Use Outcomes among Concurrent Users: A Motivational Model of Substance Use. Alcohol Clin. Exp. Res. 2019, 43, 732-740. [CrossRef] [PubMed]

79. Amrock, S.M.; Weitzman, M. Adolescents' perceptions of light and intermittent smoking in the United States. Pediatrics 2015, 135, 246-254. [CrossRef] [PubMed]

80. Godoy-Vieira, A.; Soares, C.B.; Cordeiro, L.; Campos, C.S. Inclusive and emancipatory approaches to occupational therapy practice in substance-use contexts. Can. J. Occup. Ther. 2018, 85, 307-317. [CrossRef] 